\title{
Biomass fuels are the probable risk factor for chronic obstructive pulmonary disease in rural South China
}

\author{
Shengming Liu, Yumin Zhou, Xiaoping Wang, Dali Wang, Jiachun Lu, Jingping Zheng, Nanshan \\ Zhong, Pixin Ran
}

Thorax 2007;62:889-897. doi: 10.1136/thx.2006.061457

See end of article for authors' affiliations

Correspondence to: Dr Pixin Ran, Guangzhou Institute of Respiratory Disease, The First Affiliated Hospital of Guangzhou Medical College, 195 Dongfeng Xi Road, Guangzhou 510182 P R China; pxran@gzhmc. edu.cn

Received 6 April 2006 Accepted 4 April 2007

Published Online First 3 May 2007

\begin{abstract}
Background: There is increasing evidence for a possible association between chronic obstructive pulmonary disease (COPD) and the use of biomass fuels for cooking and heating in developing countries. Data on the prevalence of COPD and objective measurements of indoor pollution from biomass fuel have not been widely available from China. A study was undertaken to investigate the prevalence of COPD in two study communities in Guangdong province in China and to measure the association between COPD and indoor biomass fuel air pollution.

Methods: A cluster disproportional random sampling survey was performed in populations aged over 40 years in urban (Liwang) and rural (Yunyan) areas in Guangdong, China. Spirometry was performed in all subjects and a post-bronchodilator ratio of the forced expiratory volume in $1 \mathrm{~s}$ to forced vital capacity of $<0.70$ was defined as COPD. Measurements of indoor and outdoor air pollutants were also performed in a random sample of households.

Results: The overall prevalence of COPD in the two areas (Liwang and Yunyan) was 9.4\%. The prevalence of COPD in both the whole population and a subpopulation of non-smoking women in rural Yunyan was significantly higher than in urban Liwang $(12.0 \%$ vs $7.4 \%$, and $7.2 \%$ vs $2.5 \%$, respectively). The use of biomass fuel was higher in rural Yunyan than in urban Liwang (88.1\% vs $0.7 \%$ ). Univariate analysis showed a significant association between COPD and exposure to biomass fuel for cooking. Multivariate analysis showed a positive association between COPD and urban/rural area (surrogate for fuel type and local exhaust ventilation in kitchen) after adjustment for sex, age group, body mass index, education, occupational exposure, respiratory disease in family, smoking status, life quality and cough in childhood; similar results were found in non-smoking women. Pollutants measurements showed that concentrations of carbon monoxide, particulate matter with an aerodynamic diameter $\leqslant 10 \mu \mathrm{m}$, sulphur dioxide and nitrogen dioxide in the kitchen during biomass fuel combustion were significantly higher than those during LPG combustion. Conclusions: Indoor pollutants from biomass fuels may be an important risk factor for COPD in rural South China.
\end{abstract}

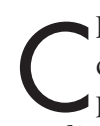
hronic obstructive pulmonary disease (COPD) is a major cause of chronic morbidity and mortality with increasing prevalence throughout the world. ${ }^{1}$ Many epidemiological studies on COPD are available from Europe and America, but data are limited on its prevalence in Asia, ${ }^{2}$ especially China.

COPD usually arises from an interaction between host factors and environmental factors. Advanced age, male sex, cigarette smoking, occupational dust exposure and low socioeconomic status are well known independent risk factors for COPD. ${ }^{3}$ Considerable attention has been given to the associations between levels of indoor and outdoor air pollutants-both gases (sulfur dioxide) and ambient particulate matter-and decreased pulmonary function in COPD. ${ }^{4}$ Inhalation of indoor air pollutants is increasingly being investigated with regard to acute morbidity, whereas chronic features and complications that may lead to respiratory disability are less well characterised. Exposure to indoor air pollution may be responsible for nearly 2 million excess deaths in developing countries and about $4 \%$ of the global health burden. ${ }^{5}$ Studies of women in developing countries exposed to various levels of indoor pollutants emitted from cooking, baking and heating with unprocessed solid fuels, including biomass and charcoal, have suggested that chronic exposures are associated with chronic airflow obstruction in adults and acute respiratory infection in children. ${ }^{6-8}$ However, these studies are mainly based on a few case reports, limited clinical data and small-scale epidemiological surveys. The effect of the indoor pollutants as a risk factor for the prevalence of COPD has not been adequately assessed in China.

While rural communities in developing countries rely mainly or exclusively on biomass fuels such as wood, agricultural crop residues, animal dung or charcoal, families in urban areas increasingly use kerosene, liquid petroleum gas (LPG) or electricity as the major source of domestic energy. Evidence from a limited number of studies suggests that the smoke from biomass fuel combustion may be associated with functional and structural pathological changes in the respiratory system, ${ }^{9}{ }^{10}$ but confounding by other factors associated with a traditional lifestyle cannot be ruled out. In addition, little is known about the relationship between the indoor air pollution exposure patterns during biomass fuel combustion and COPD.

Our objectives were to compare the prevalence of COPD in the urban populations (Liwang) with that in the rural subsistence populations (Yunyan) in Guangdong, China (fig 1); to explore the difference in COPD prevalence with exposure to other related risk factors between the two communities; and to assess the potential effects of indoor and outdoor air pollutants from biomass fuel combustion on the

Abbreviations: BMI, body mass index; $C O$, carbon monoxide; COPD, chronic obstructive pulmonary disease; $\mathrm{FEV}_{1}$, forced expiratory volume in $1 \mathrm{~s}$; FVC, forced vital capacity; LPG, liquid petroleum gas; $\mathrm{NO}_{2}$, nitrogen dioxide; $\mathrm{PM}_{10}$, particulate matter with aerodynamic diameter $\leqslant 10 \mu \mathrm{m}$; $\mathrm{SO}_{2}$, sulphur dioxide 


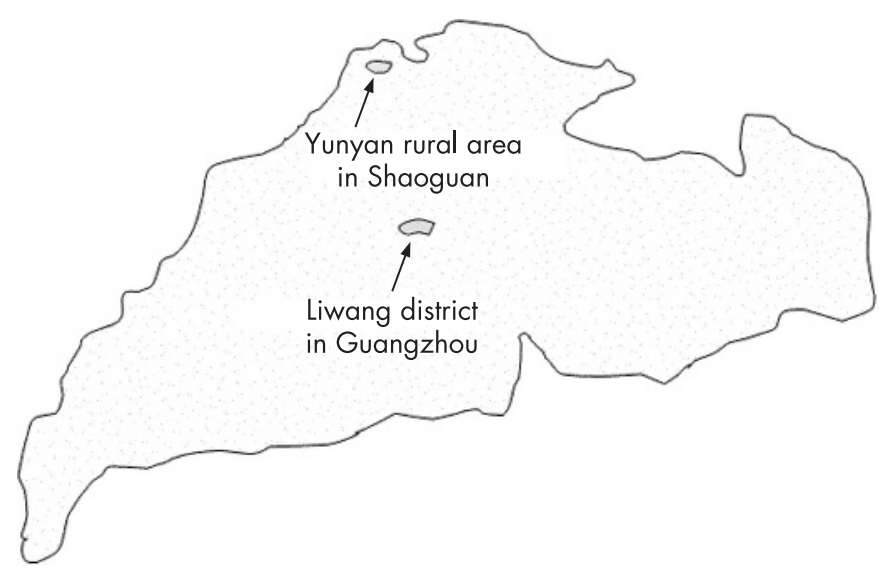

Figure 1 Yunyan and Liwang communities in Guangdong province of China.

prevalence of COPD. This is the first large-scale epidemiological study to evaluate the association between indoor biomass fuel air pollution and COPD in China.

\section{METHODS}

\section{Study design}

This was a population-based cross-sectional epidemiological survey of COPD. A multistage cluster sampling strategy was used in a population aged $\geqslant 40$ years from a rural area and an urban city of Guangdong in China. Sample size was calculated based on the prevalence of COPD in a pre-survey study. We aimed to locate about 1600 eligible participants in each area including a $10 \%$ expected refusal rate. Our preliminary study revealed that the prevalence of COPD in non-smoking women in urban Liwang and rural Yunyan areas was in a ratio of about $1: 2$. This difference in the prevalence of COPD warrants further investigation.

\section{Study population}

The first step in the sampling process was the stratification of census tracts. Owing to a big socioeconomic difference between the rural and urban regions, an urban district and a rural county were randomly selected. At the second stage of sampling, an urban street or a rural township from each of the selected urban district and rural county were randomly selected. Finally, a randomised cluster sampling method was employed to select urban communities or villages (cluster units). The number of selected clusters varied with the size of population in the communities or villages. In the selected sample clusters, all residents aged $\geqslant 40$ years according to the latest census (by local police stations where residential registry data were kept electronically) were recruited. Subjects aged $<40$ years were not enrolled. Those temporarily out of reach were given a home interview on a later occasion.

Two study sites, Yunyan and Liwang, were selected according to their representative lifestyle, similar geographical locations and available community centres. Yunyan is located in Shaoguan city, a self-subsistent rural area in northern Guangdong with a population of about 14000 . There is no
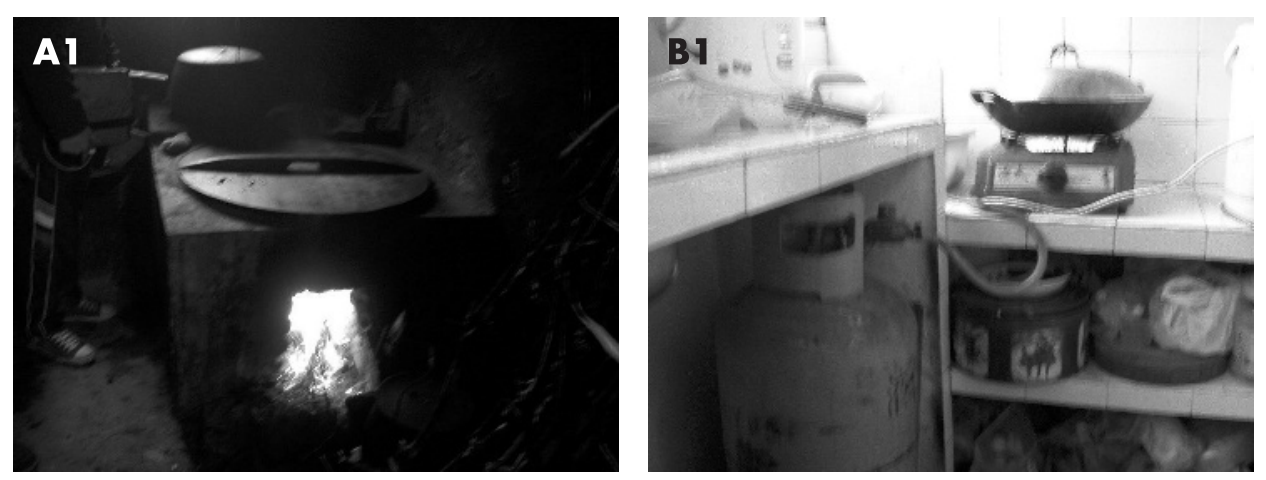

Figure 2 Cooking in (A) rural Yunyan and (B) urban Liwang.
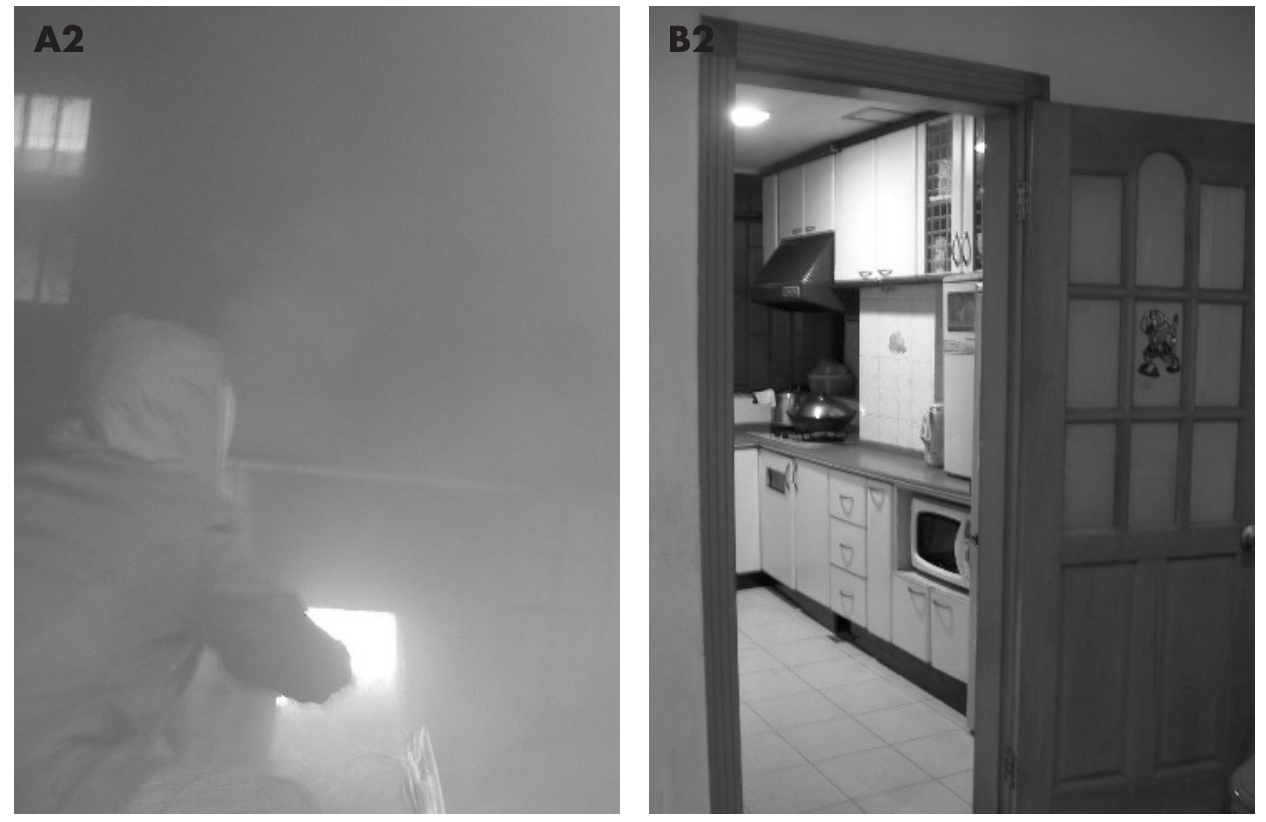
Table 1 Characteristics of study populations in urban Liwang and rural Yunyan*

\begin{tabular}{|c|c|c|c|c|}
\hline & $\begin{array}{l}\text { Urban Liwang } \\
(n=1818)\end{array}$ & $\begin{array}{l}\text { Rural Yunyan } \\
(n=1468)\end{array}$ & $\begin{array}{l}\text { Total } \\
(n=3286)\end{array}$ & $\begin{array}{l}\text { p Value } \\
\text { (Liwang vs } \\
\text { Yunyan) }\end{array}$ \\
\hline Sex & & & & 0.156 \\
\hline Men & $730(40.2)$ & $640(43.6)$ & $1370(41.7)$ & \\
\hline Women & $1088(59.8)$ & $828(56.4)$ & $1916(58.3)$ & \\
\hline Age group (years) & & & & $<0.001$ \\
\hline $40-49$ & $529(29.1)$ & $600(40.9)$ & $1129(34.4)$ & \\
\hline $50-59$ & $381(21.0)$ & $372(25.3)$ & $753(22.9)$ & \\
\hline $60-69$ & $525(28.9)$ & $344(23.4)$ & $869(26.4)$ & \\
\hline$\geqslant 70$ & $383(21.1)$ & $152(10.4)$ & $535(16.3)$ & \\
\hline Education (years) & & & & $<0.001$ \\
\hline 0 & $175(9.6)$ & $870(59.3)$ & $1045(31.8)$ & \\
\hline $1-6$ & 585 (32.2) & $433(29.5)$ & $1018(31.0)$ & \\
\hline$\geqslant 7$ & $1058(58.2)$ & 165 (11.2) & $1223(37.2)$ & \\
\hline Smoking status & & & & $<0.001$ \\
\hline Non-smokers without ETS† & $626(34.4)$ & $268(18.3)$ & $894(27.2)$ & \\
\hline Non-smokers with ETS & $553(30.4)$ & $636(43.3)$ & $1189(36.2)$ & \\
\hline Smokers $<15$ pack-years & 191 (10.5) & $132(9.0)$ & $323(9.8)$ & \\
\hline Smokers $\geqslant 15$ pack-years & 448 (24.6) & $432(29.4)$ & $880(26.8)$ & \\
\hline Occupational exposure to dust & & & & $<0.001$ \\
\hline Yes & $433(23.8)$ & $1413(96.3)$ & $1846(56.2)$ & \\
\hline No & $1385(76.2)$ & $55(3.7)$ & $1440(43.8)$ & \\
\hline Respiratory disease in family & & & & 0.001 \\
\hline Yes & $354(19.5)$ & $367(25.0)$ & $721(21.9)$ & \\
\hline No & $1464(80.5)$ & $1101(75.0)$ & $2565(78.1)$ & \\
\hline Cough in childhood & & & & $<0.001$ \\
\hline Often/sometimes & $154(8.5)$ & $23(1.6)$ & $177(5.4)$ & \\
\hline Seldom & $1664(91.5)$ & 1445 (98.4) & $3109(94.6)$ & \\
\hline BMI $\left(\mathrm{kg} / \mathrm{m}^{2}\right)$ & & & & $<0.001$ \\
\hline$<18.5$ & $166(9.1)$ & $53(3.6)$ & $219(6.7)$ & \\
\hline $18.5-23.9$ & $1008(55.5)$ & $1022(69.6)$ & $2030(61.8)$ & \\
\hline$\geqslant 24.0$ & $644(35.4)$ & $393(26.8)$ & $1037(31.6)$ & \\
\hline Life quality§ & & & & $<0.001$ \\
\hline Poor & $92(5.1)$ & $377(25.7)$ & $469(14.3)$ & \\
\hline General & $1492(82.1)$ & $1048(71.4)$ & $2540(77.3)$ & \\
\hline Good & 234 (12.9) & $43(2.9)$ & $277(8.4)$ & \\
\hline Fuel type & & & & $<0.001$ \\
\hline LPG & $1793(98.6)$ & $15(1.0)$ & $1808(55.0)$ & \\
\hline Coal & $12(0.7)$ & $160(10.9)$ & $172(5.2)$ & \\
\hline Biomass & $13(0.7)$ & $1293(88.1)$ & $1306(39.8)$ & \\
\hline \multicolumn{4}{|c|}{ Local exhaust ventilation in kitchen } & $<0.001$ \\
\hline Yes & $1610(88.6)$ & $10(0.7)$ & $1620(49.3)$ & \\
\hline No & $208(11.4)$ & $1458(99.3)$ & $1666(50.7)$ & \\
\hline COPD & & & & 0.004 \\
\hline Yes & $134(7.4)$ & $176(12.0)$ & $310(9.4)$ & \\
\hline No & $1684(92.6)$ & $1292(88.0)$ & $2976(90.6)$ & \\
\hline
\end{tabular}

ETS, environmental tobacco smoke; BMI, body mass index; LPG, liquid petroleum gas. *Data shown as number (\%) of observations.

†Environmental tobacco smoke exposure (duration of passive smoking over 5 years).

$\ddagger$ Chronic bronchitis, emphysema, bronchial asthma or COPD in family members in the households.

$\S$ Defined by family income.

- Crop residues, wood, etc.

major industry and little motorised transport. Biomass fuels are the major source of fuel for cooking, baking and heating. Cooking is mainly done indoors with an open-fire traditional cooking stove in a small adobe kitchen with thatched or tile roofs and without any ventilation (fig 2A). During cooking the biomass fuels are placed in a hole that is carved out of the middle part of the stove below the area for the pots and pans. The kitchens are filled with heavy smoke during biomass fuel combustion.

Liwang is part of Guangzhou city, an urban area in central Guangdong with a population of about 520 000. It is about $400 \mathrm{~km}$ south of Yunyan and is in an early stage of economic development. There is no heavy industry but modest motorised transport. Modern fuels such as liquid petroleum gas (LPG) are used as the major source of fuel for cooking. Cooking is mainly done either in an open or closed kitchen adjacent to the living room within the house (fig $2 \mathrm{~B}$ ); some houses have installed a local exhaust ventilation facility above the stove where heavy smoke is seldom observed during cooking.

\section{Pollutant measurement}

During cooking, air pollutant concentrations of sulfur dioxide $\left(\mathrm{SO}_{2}\right)$, nitrogen dioxide $\left(\mathrm{NO}_{2}\right)$, carbon monoxide $(\mathrm{CO})$ and particulate matter with an aerodynamic diameter $\leqslant 10 \mu \mathrm{m}$ $\left(\mathrm{PM}_{10}\right)$ were measured. Traditionally, most women do the cooking for the family. Samples of indoor and outdoor air pollutants were taken in the households of every 20th nonsmoking woman in urban Liwang and every loth non-smoking woman in rural Yunyan.

During cooking with biomass, charcoal or gas in the selected households, indoor concentrations of air pollutants were monitored in the kitchen and living room while outdoor concentrations of the pollutants were also measured. All air sampling was carried out at a height of 1.2-1.5 $\mathrm{m}$ from the floor of each household. Three measurements were obtained from three sampling sites at a distance of $1 \mathrm{~m}$ from the centre of the cooking stove inside the kitchen. Three measurements were obtained from three random sampling sites inside the living room at least $3 \mathrm{~m}$ from the kitchen. Three outdoor 
Table 2 Prevalence of COPD and outcome of logistic regression analysis in urban Liwang and rural Yunyan*

\begin{tabular}{|c|c|c|c|c|c|}
\hline & $\begin{array}{l}\text { COPD } \\
\text { n (\%) }\end{array}$ & Crude OR $(95 \% \mathrm{Cl})$ & p Value & Adjusted OR $(95 \% \mathrm{Cl})$ & p Value \\
\hline Areat & & & 0.004 & & 0.037 \\
\hline Rural Yunyan & $176(12.0)$ & 1.71 (1.26 to 2.33 ) & & 1.83 (1.05 to 3.19$)$ & \\
\hline Urban Liwang & $134(7.4)$ & 1.00 (reference) & & 1.00 (reference) & \\
\hline Sext & & & $<0.001$ & & $<0.001$ \\
\hline Men & 218 (15.9) & 3.87 (3.04 to 4.92 ) & & $2.90(2.20$ to 3.82$)$ & \\
\hline Women & $92(4.8)$ & 1.00 (reference) & & 1.00 (reference) & \\
\hline Age group (years) $\dagger$ & & & $<0.001$ & & $<0.001$ \\
\hline $40-49$ & $41(3.6)$ & 1.00 (reference) & & 1.00 (reference) & \\
\hline $50-59$ & $45(6.0)$ & 1.72 (1.15 to 2.55$)$ & & 1.57 (0.97 to 2.55$)$ & \\
\hline $60-69$ & $113(13.0)$ & 3.97 (2.14 to 7.33$)$ & & 3.97 (2.04 to 7.74$)$ & \\
\hline$\geqslant 70$ & $111(20.7)$ & 7.53 (4.48 to 12.64$)$ & & 7.77 (4.25 to 14.21$)$ & \\
\hline Education (years) $\dagger$ & & & 0.001 & & 0.047 \\
\hline 0 & $117(11.2)$ & 1.78 (1.39 to 2.29$)$ & & $1.68(1.01$ to 2.81$)$ & \\
\hline $1-6$ & $112(11.0)$ & 1.73 (1.17 to 2.55$)$ & & $1.09(0.75$ to 1.58$)$ & \\
\hline$\geqslant 7$ & $81(6.6)$ & 1.00 (reference) & & 1.00 (reference) & \\
\hline Smoking status $†$ & & & $<0.001$ & & 0.029 \\
\hline Non-smokers without ETS & $54(6.0)$ & 1.00 (reference) & & 1.00 (reference) & \\
\hline Non-smokers with ETS & $60(5.0)$ & $0.82(0.59$ to 1.15$)$ & & 1.33 (0.85 to 2.08$)$ & \\
\hline Smokers $<15$ pack-years & $37(11.4)$ & 2.02 (1.06 to 3.85 ) & & $1.40(0.71$ to 2.75$)$ & \\
\hline Smokers $\geqslant 15$ pack-years & 159 (18.1) & 3.53 (2.51 to 4.97$)$ & & 1.83 (1.14 to 2.95$)$ & \\
\hline Occupational exposure to dust & & & 0.018 & & 0.364 \\
\hline Yes & $203(11.0)$ & 1.51 (1.10 to 2.07$)$ & & 1.19 (0.78 to 1.82$)$ & \\
\hline No & $107(7.4)$ & 1.00 (reference) & & 1.00 (reference) & \\
\hline Respiratory disease in family $\dagger$ & & & 0.002 & & $<0.001$ \\
\hline Yes & 99 (13.7) & 1.72 (1.30 to 2.28$)$ & & 1.98 (1.62 to 2.41$)$ & \\
\hline No & $211(8.2)$ & 1.00 (reference) & & 1.00 (reference) & \\
\hline Cough in childhoodt & & & 0.001 & & $<0.001$ \\
\hline $\begin{array}{l}\text { Often/sometimes } \\
\text { Seldom }\end{array}$ & $\begin{array}{l}33(18.6) \\
277(8.9)\end{array}$ & $\begin{array}{l}2.30 \text { (1.58 to } 3.34 \text { ) } \\
1.00 \text { (reference) }\end{array}$ & & $\begin{array}{l}3.23 \text { (2.17 to } 4.82 \text { ) } \\
1.00 \text { (reference) }\end{array}$ & \\
\hline BMI $\left(\mathrm{kg} / \mathrm{m}^{2}\right) \dagger$ & & & $<0.001$ & & $<0.001$ \\
\hline$\geqslant 24.0$ & $45(4.3)$ & $0.39(0.23$ to 0.66$)$ & & $0.45(0.26$ to 0.79$)$ & \\
\hline $18.5-23.9$ & $212(10.4)$ & 1.00 (reference) & & 1.00 (reference) & \\
\hline$<18.5$ & $53(24.2)$ & $2.76(2.07$ to 3.68$)$ & & 2.88 (1.97 to 4.23$)$ & \\
\hline Life quality† & & & 0.123 & & 0.330 \\
\hline Poor & $43(9.2)$ & 1.51 (0.92 to 2.48$)$ & & $0.79(0.38$ to 1.65$)$ & \\
\hline General & $250(9.8)$ & $1.60(0.95$ to 2.69$)$ & & 1.05 (0.60 to 1.85$)$ & \\
\hline Good & $17(6.1)$ & 1.00 (reference) & & 1.00 (reference) & \\
\hline Fuel typef & & & 0.019 & & 0.021 \\
\hline LPG & $132(7.3)$ & 1.00 (reference) & & & \\
\hline Coal & $21(12.2)$ & 1.55 (0.74 to 3.22$)$ & & & \\
\hline Biomass & $157(12.0)$ & 1.72 (1.27 to 2.35$)$ & & & \\
\hline Local exhaust ventilation in kitchen $\neq$ & & & $<0.001$ & & 0.011 \\
\hline Yes & $111(6.8)$ & 1.00 (reference) & & & \\
\hline No & 199 (11.9) & 1.85 (1.45 to 2.36$)$ & & & \\
\hline
\end{tabular}

ETS, environmental tobacco smoke; BMI, body mass index; LPG, liquid petroleum gas.

*Data of 3286 participants were analysed and are presented as number (\%) of observations and OR $(95 \% \mathrm{Cl})$.

†These variables were included in the multivariate logistic regression model.

†Fuel type and local exhaust ventilation in kitchen excluded from multivariate model because they were collinear with urban/rural residence.

measurements were obtained as environmental control samples from three random sampling sites outside the study household at least $20 \mathrm{~m}$ from the household.

Air pollutants were monitored using Interscan 4140 (Interscan Co, Chatsworth, California, USA) for CO, automatic dust monitor (P-5L2C, Peking, China) for $\mathrm{PM}_{10}$, Interscan 4240 (Interscan Co) for $\mathrm{SO}_{2}$ and Interscan 4150 (Interscan Co) for $\mathrm{NO}_{2}$ measurements. These monitors were direct reading instruments. Each measurement was maintained for over $5 \mathrm{~min}$ and three readings were taken for each measurement to calculate the mean concentration.

\section{Measurement of health outcome}

The survey was conducted from September 2002 to March 2003. All interviews and examinations took place in community centres of the study populations. They were given individual interviews by trained interviewers using a standardised questionnaire. The questionnaire included factors potentially associated with COPD such as age, sex, education level, smoking history, occupation, domestic cooking fuels used in previous 10 years, respiratory problems in childhood and other risk factors. Those with any of the following within the previous
2 months were excluded as they were unable to undergo spirometry: thoracic or abdominal surgery, heart attack, current tuberculosis, eye surgery (or retinal detachment) or hospitalisation for a cardiovascular problem. A portable spirometer (Microloop 3535, Micro Medical Ltd, UK) was used to test the lung function of each eligible inhabitant in the study households. The spirometer was calibrated daily with a 3-litre syringe before any test was begun. Quality control procedures were followed according to American Thoracic Society (ATS) guidelines. ${ }^{11}$ For every test subject, three acceptable forced expiratory volume in $\mathrm{l} \mathrm{s}\left(\mathrm{FEV}_{1}\right)$ and forced vital capacity (FVC) measurements were obtained. COPD was defined as a ratio of the postbronchodilator $\mathrm{FEV}_{1}$ to $\mathrm{FVC}$ of $<0.70$ according to the Global Initiative for Chronic Obstructive Lung Disease (GOLD) criteria. $^{12}$

The characteristics of the study populations are shown in table 1 .

\section{Statistical methods}

Statistical analyses were performed with STATA software Version 7.0 (STATA Corporation, College Station, Texas, USA) which allows analysis of clustered data. All categorical variables 


\begin{tabular}{|c|c|c|c|c|}
\hline & $\begin{array}{l}\text { Urban Liwang } \\
(n=985)\end{array}$ & $\begin{array}{l}\text { Rural Yunyan } \\
(\mathrm{n}=824)\end{array}$ & $\begin{array}{l}\text { Total } \\
(n=1809)\end{array}$ & $\begin{array}{l}\text { p Value (Liwang } \\
\text { vsYunyan) }\end{array}$ \\
\hline Age group (years) & & & & $<0.001$ \\
\hline $40-49$ & $321(32.6)$ & $360(43.7)$ & $681(37.6)$ & \\
\hline $50-59$ & $239(24.3)$ & $222(26.9)$ & $461(25.5)$ & \\
\hline $60-69$ & $276(28.0)$ & $168(20.4)$ & $444(24.5)$ & \\
\hline$\geqslant 70$ & $149(15.1)$ & $74(9.0)$ & $223(12.3)$ & \\
\hline Education (years) & & & & $<0.001$ \\
\hline 0 & $126(12.8)$ & $706(85.7)$ & $832(46.0)$ & \\
\hline $1-6$ & $330(33.5)$ & $109(13.2)$ & $439(24.3)$ & \\
\hline$\geqslant 7$ & $529(53.7)$ & $9(1.1)$ & $538(29.7)$ & \\
\hline ETS & & & & $<0.001$ \\
\hline No & $440(44.7)$ & $188(22.8)$ & $628(34.7)$ & \\
\hline Yes & $545(55.3)$ & 636 (77.2) & $1181(65.3)$ & \\
\hline Occupational exposure to dus & & & & $<0.001$ \\
\hline Yes & $244(24.8)$ & $812(98.5)$ & $1056(58.4)$ & \\
\hline No & $741(75.2)$ & $12(1.5)$ & $753(41.6)$ & \\
\hline Respiratory disease in family & & & & 0.097 \\
\hline Yes & $185(18.8)$ & $174(21.1)$ & $359(19.8)$ & \\
\hline No & $800(81.2)$ & $650(78.9)$ & $1450(80.2)$ & \\
\hline Cough in childhood & & & & $<0.001$ \\
\hline Often/sometimes & $70(7.1)$ & $11(1.3)$ & $81(4.5)$ & \\
\hline $\begin{array}{l}\text { Seldom } \\
\text { BMI }\left(\mathrm{kg} / \mathrm{m}^{2}\right)\end{array}$ & $415(92.4)$ & $813(98.7)$ & $1 / 28$ (95.5) & 0.005 \\
\hline$<18.5$ & $67(6.8)$ & $33(4.0)$ & $100(5.5)$ & \\
\hline $18.5-23.9$ & $539(54.7)$ & $537(65.2)$ & $1076(59.5)$ & \\
\hline$\geqslant 24.0$ & $379(38.5)$ & $254(30.8)$ & $633(35.0)$ & \\
\hline Life quality & & & & $<0.001$ \\
\hline Poor & $44(4.5)$ & $247(30.0)$ & $291(16.1)$ & \\
\hline General & $815(82.7)$ & $558(67.7)$ & 1373 (75.9) & \\
\hline Good & $126(12.8)$ & $19(2.3)$ & $145(8.0)$ & \\
\hline Fuel type & & & & $<0.001$ \\
\hline LPG & $974(98.9)$ & $1(0.1)$ & 975 (53.9) & \\
\hline Coal & $8(0.8)$ & $82(10.0)$ & $90(5.0)$ & \\
\hline Biomass & $3(0.3)$ & $741(89.9)$ & $744(41.1)$ & \\
\hline Local exhaust ventilation in & & & & $<0.001$ \\
\hline $\begin{array}{l}\text { Kitchen } \\
\text { Yes }\end{array}$ & $888(90.2)$ & $6(0.7)$ & $894(49.4)$ & \\
\hline No & $97(9.8)$ & $818(99.3)$ & $915(50.6)$ & \\
\hline
\end{tabular}

ETS, environmental tobacco smoke; BMI, body mass index; LPG, liquid petroleum gas.

*Data shown as number (\%) of observations.

were treated as dummy categorical variables; when appropriate, some were treated as ordinal variables. Svytab commands were used to analyse the frequency distributions of demographic variables and the prevalence of COPD in the two study communities. The difference in air pollutant concentrations at different locations and cooking fuel types was analysed using analysis of variance (ANOVA) after transformation to natural logarithm. Calculations of odds ratios (ORs) and 95\% confidence intervals (CI) for the association between COPD and air pollutant concentrations and potential risk factors were performed with univariate logistic regression and multivariate logistic regression using the svylogit commands which took account of sampling strategy. Urban/rural, sex, age group, education, smoking status, occupational exposure to dust, respiratory disease in family, cough in childhood, body mass index (BMI) and life quality were included in the multivariate logistic regression models. Because the variables of fuel type and local exhaust ventilation in kitchen were surrogates for urban/rural residence, we excluded these variables from the multivariate models. Because variables of sex and smoking were important confounders, the association between COPD and potential risk factors was analysed in the subpopulation of non-smoking women. Because concentrations of individual pollutants were correlated with each other, the association between COPD and the concentrations of $\mathrm{SO}_{2}, \mathrm{NO}_{2}, \mathrm{PM}_{10}, \mathrm{CO}$ and the scores from principal components analysis of their concentrations were respectively analysed and adjusted by area, age group, education, environmental tobacco smoke, occupational exposure, respiratory disease in family and cough in childhood.

\section{RESULTS}

In total, 3449 subjects were surveyed with a response rate of $81.3 \%(3449 / 4243)$. There were 3286 subjects (1370 men and 1916 women) with full questionnaire information, good quality control and reliable spirometric measurements, giving a valid response rate of $77.4 \%(3286 / 4243), 73.9 \%(1818 / 2461)$ in urban Liwang and $82.4 \%(1468 / 1782)$ in rural Yunyan $(\mathrm{p}<0.01)$. The valid response rate of men in urban Liwang was lower than in rural Yunyan $(60.4 \%$ vs $70.2 \%, \mathrm{p}<0.01)$. However, there was no difference in the valid response rate of women between the two areas $(86.8 \%$ vs $87.9 \%, p=0.458)$. The valid response rate in subjects aged $>60$ years in urban Liwang was higher than in rural Yunyan $(90.9 \%$ vs $84.3 \%, \mathrm{p}<0.01)$ while, in subjects aged $<60$ years, it was lower in urban Liwang than in rural Yunyan $(61.6 \%$ vs $81.4 \%, \mathrm{p}<0.01)$.

In Yunyan and Liwang areas there were approximately the same proportions of men and women (men $43.6 \%$ vs $40.2 \%$; women $56.4 \%$ vs $59.8 \%$, respectively). In rural Yunyan there was a significantly higher proportion of the population with lower education levels (88.8\% for 0-6 years), more smokers (total 38.4\%), more occupational exposure to dust (96.3\%) and a higher incidence of family history of respiratory disease $(25.0 \%)$. In urban Liwang there was a significantly higher proportion with higher education levels $(58.2 \%$ for $\geqslant 7$ years) and good ventilation in the kitchen. In rural Yunyan $88.1 \%$ of 
Table 4 Prevalence of COPD and outcome of logistic regression analysis for subpopulation of non-smoking women in urban Liwang and rural Yunyan*

\begin{tabular}{|c|c|c|c|c|c|}
\hline & $\begin{array}{l}\text { COPD } \\
\text { n (\%) }\end{array}$ & Crude OR $(95 \% \mathrm{Cl})$ & p Value & Adjusted OR $(95 \% \mathrm{Cl})$ & p Value \\
\hline Areat & & & 0.005 & & 0.035 \\
\hline Rural Yunyan & $59(7.2)$ & 2.96 (1.55 to 5.67$)$ & & $3.60(1.13$ to 11.52$)$ & \\
\hline Urban Liwang & $25(2.5)$ & 1.00 (reference) & & 1.00 (reference) & \\
\hline Age group (years) $\dagger$ & & & $<0.001$ & & $<0.001$ \\
\hline $40-49$ & $17(2.5)$ & 1.00 (reference) & & 1.00 (reference) & \\
\hline $50-59$ & $13(2.8)$ & 1.09 (0.55 to 2.19$)$ & & 1.02 (0.48 to 2.13 ) & \\
\hline $60-69$ & $27(6.1)$ & 2.47 (1.57 to 3.87$)$ & & 3.12 (2.03 to 4.79$)$ & \\
\hline$\geqslant 70$ & $27(12.1)$ & 5.61 (3.78 to 8.30$)$ & & 7.33 (3.94 to 13.65$)$ & \\
\hline Education (years) $\dagger$ & & & $<0.001$ & & 0.164 \\
\hline 0 & $60(7.2)$ & 6.81 (3.36 to 13.78 ) & & 2.41 (0.72 to 8.01$)$ & \\
\hline $1-6$ & $18(4.1)$ & 3.71 (1.38 to 9.98$)$ & & $2.34(0.72$ to 7.58$)$ & \\
\hline$\geqslant 7$ & $6(1.1)$ & 1.00 (reference) & & 1.00 (reference) & \\
\hline ETS† & & & 0.280 & & 0.671 \\
\hline Yes & $66(5.6)$ & $1.29(0.78$ to 2.15$)$ & & 1.10 (0.66 to 1.83 ) & \\
\hline No & $18(2.9)$ & 1.00 (reference) & & 1.00 (reference) & \\
\hline Occupational exposure to dust & & & 0.003 & & 0.980 \\
\hline Yes & $66(6.2)$ & 2.67 (1.55 to 4.61$)$ & & 0.99 (0.34 to 2.86$)$ & \\
\hline No & $18(2.4)$ & 1.00 (reference) & & 1.00 (reference) & \\
\hline Respiratory disease in family $\dagger$ & & & 0.002 & & 0.001 \\
\hline Yes & $29(8.1)$ & 2.20 (1.46 to 3.31$)$ & & 3.14 (1.89 to 5.21$)$ & \\
\hline No & 55 (3.8) & 1.00 (reference) & & 1.00 (reference) & \\
\hline Cough in childhood $\dagger$ & & & 0.130 & & 0.006 \\
\hline $\begin{array}{l}\text { Offen/sometimes } \\
\text { Seldom }\end{array}$ & $\begin{array}{l}8(9.9) \\
76(4.4)\end{array}$ & $\begin{array}{l}2.40 \text { (0.73 to } 7.92) \\
1.00 \text { (reference) }\end{array}$ & & $\begin{array}{l}4.66 \text { (1.78 to } 12.22) \\
1.00 \text { (reference) }\end{array}$ & \\
\hline BMI $\left(\mathrm{kg} / \mathrm{m}^{2}\right) \dagger$ & & & $<0.001$ & & $<0.001$ \\
\hline$\geqslant 24.0$ & $13(2.1)$ & $0.41(0.19$ to 0.87$)$ & & $0.41(0.20$ to 0.85$)$ & \\
\hline $18.5-23.9$ & 15 (1.4) & 1.00 (reference) & & 1.00 (reference) & \\
\hline$<18.5$ & $56(56)$ & $3.23(2.16$ to 4.83$)$ & & 3.15 (2.36 to 4.21$)$ & \\
\hline Life quality $\dagger$ & & & 0.048 & & 0.315 \\
\hline Poor & $17(5.8)$ & 4.68 (0.87 to 25.34$)$ & & $1.32(0.25$ to 6.90$)$ & \\
\hline General & $65(4.7)$ & 3.64 (0.74 to 17.80$)$ & & 2.30 (0.43 to 12.29$)$ & \\
\hline Good & $2(1.4)$ & 1.00 (reference) & & 1.00 (reference) & \\
\hline Fuel type & & & 0.002 & & 0.019 \\
\hline LPG & $24(2.5)$ & 1.00 (reference) & & & \\
\hline Coal & $6(6.7)$ & $2.77(0.83$ to 9.26$)$ & & & \\
\hline Biomass & $54(7.3)$ & 3.11 (1.63 to 5.94$)$ & & & \\
\hline Local exhaust ventilation in kitchen $\neq$ & & & 0.003 & & 0.082 \\
\hline Yes & $21(2.3)$ & 1.00 (reference) & & & \\
\hline No & $63(6.9)$ & 3.04 (1.64 to 5.63$)$ & & & \\
\hline
\end{tabular}

ETS, environmental tobacco smoke; BMI, body mass index; LPG, liquid petroleum gas.

*Data of 1089 participants were analysed and are shown as number $(\%)$ of observations and OR $(95 \% \mathrm{CI})$.

†These variables were included in the multivariate logistic regression model.

†Fuel type and local exhaust ventilation in kitchen excluded from multivariate model because they were collinear with urban/rural residence.

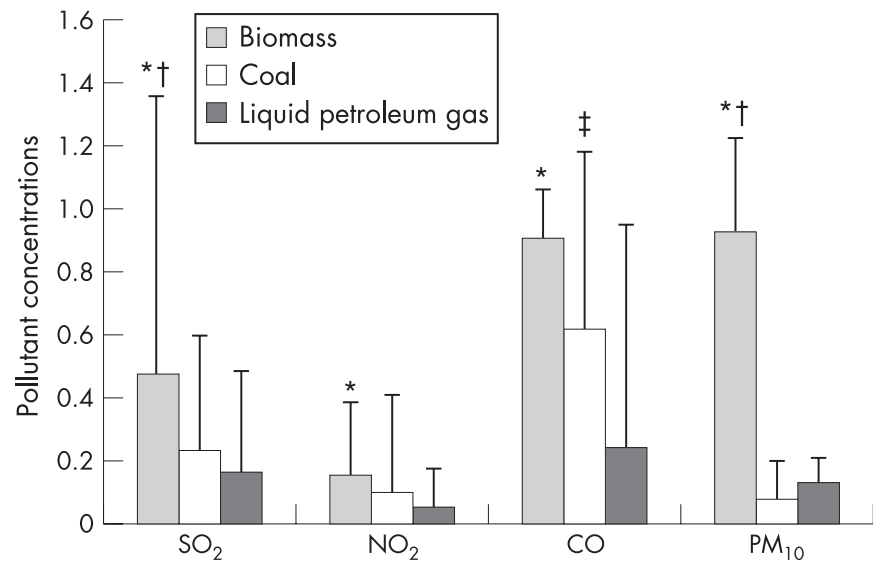

Figure 3 Comparison of pollutant concentrations in the kitchen from burning biomass, coal and liquid petroleum gas (LPG) in rural Yunyan and urban Liwang. Data presented as geometric mean (SD). The total number of samples is 194 with 120 for biomass, 14 for coal and 60 for LPG. Pollutant concentrations are in $\mathrm{mg} / \mathrm{m}^{3}$ except for $\mathrm{CO}$ which is in $10 \times \mathrm{mg} /$ $\mathrm{m}^{3}$. $\mathrm{SO}_{2}$, sulphur dioxide; $\mathrm{NO}_{2}$, nitrogen dioxide; $\mathrm{CO}$, carbon monoxide; $\mathrm{PM}_{10}$, particulate matter with aerodynamic diameter $\leqslant 10 \mu \mathrm{m} .{ }^{*} \mathrm{p}<0.05 \mathrm{vs}$ LPG; $\mathrm{tp}<0.05$ vs coal; $\ddagger \mathrm{p}<0.05$ vs LPG.

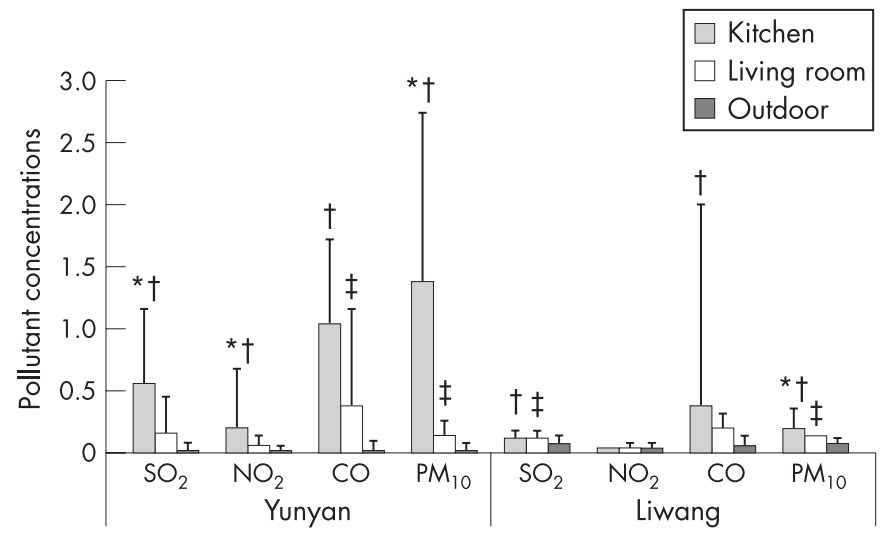

Figure 4 Indoor and outdoor pollutant concentrations in rural Yunyan and urban liwang. Data presented as geometric mean (SD), $n=10$. Pollutant concentrations are in $\mathrm{mg} / \mathrm{m}^{3}$ except for $\mathrm{CO}$ which is in $10 \times \mathrm{mg} /$ $\mathrm{m}^{3} . \mathrm{SO}_{2}$, sulphur dioxide; $\mathrm{NO}_{2}$, nitrogen dioxide; $\mathrm{CO}$, carbon monoxide; $\mathrm{PM}_{10}$, particulate matter with aerodynamic diameter $\leqslant 10 \mu \mathrm{m}$. ${ }^{*} \mathrm{p}<0.05$ kitchen vs living room; $\uparrow p<0.05$ kitchen vs outdoor; $\ddagger p<0.05$ living room vs outdoor. 


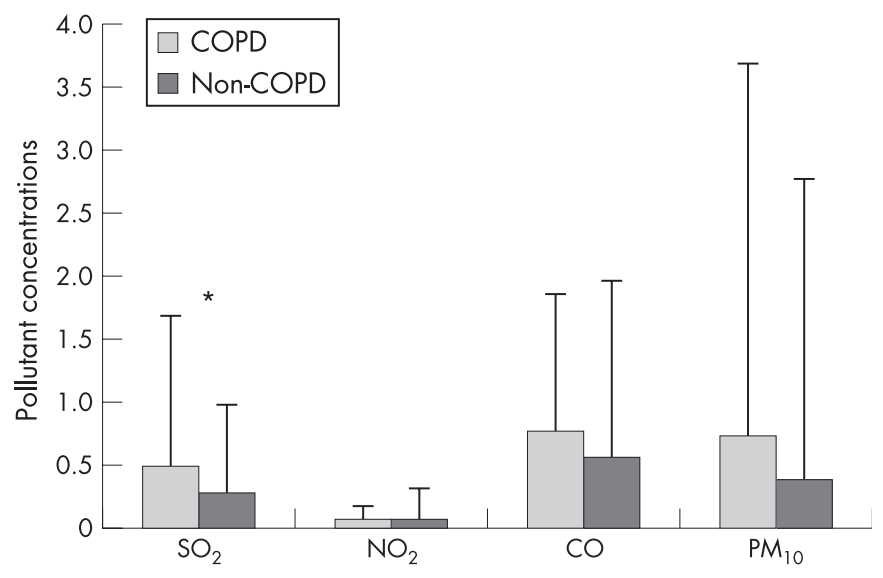

Figure 5 Pollutant concentrations in the kitchen of subjects with and without chronic obstructive pulmonary disease (COPD). Data presented as geometric mean (SD); number of samples 20 and 174 respectively. Pollutant concentrations are in $\mathrm{mg} / \mathrm{m}^{3}$ except for $\mathrm{CO}$ which is in $10 \times \mathrm{mg} /$ $\mathrm{m}^{3}$. $\mathrm{SO}_{2}$, sulphur dioxide; $\mathrm{NO}_{2}$, nitrogen dioxide; $\mathrm{CO}$, carbon monoxide; $\mathrm{PM}_{10}$, particulate matter with aerodynamic diameter $\leqslant 10 \mu \mathrm{m}$. ${ }^{*} \mathrm{p}<0.05$ COPD vs non-COPD.

the communities used biomass fuels. The most commonly used biomass fuels were wood and agricultural crop residues, but no animal dung was used. A smaller number of households used coal $(10.9 \%)$, but always in combination with wood and/or agricultural crop residues. About $98.6 \%$ of households in urban Liwang used LPG, rarely in combination with biomass fuels or coal (both $0.7 \%$ ).

The overall prevalence of COPD in Liwang and Yunyan areas was $9.4 \%$, with a significantly higher prevalence of COPD in rural Yunyan than in urban Liwang $(12.0 \%$ vs $7.4 \%, p<0.01)$. In both Yunyan and Liwang the prevalence of COPD in men was significantly higher than in women $(15.9 \%$ vs $4.8 \%, \mathrm{p}<0.01$, table 2). There were more smoking women in Liwang than in Yunyan (9.5\% vs $0.5 \%)$, but the prevalence of COPD in women in Yunyan was higher than in Liwang (7.1\% vs 3.0\%) (data not shown). In particular, the prevalence of COPD in non-smoking women in rural Yunyan was higher than in urban Liwang $(7.2 \%$ vs $2.5 \%$ ).

Univariate analysis showed significant associations between COPD and area, sex, age, education, smoking status, BMI, occupational exposure to dust, family history of respiratory disease, cough in childhood, local exhaust ventilation in kitchen and cooking using biomass fuel. Multivariate logistic regression analyses showed that area, sex, age, education, BMI, smoking status, respiratory disease in family and cough in childhood were significantly associated with COPD (fuel type and local exhaust ventilation in kitchen were excluded from the multivariate model because they were collinear with urban/rural residence, table 2).

In women who did not smoke there was more passive smoking $(77.2 \%)$, more occupational exposure to dust (98.5\%), lower education levels (0-6 years, 98.9\%) and a higher prevalence of COPD (7.2\%) in rural Yunyan (tables 3 and 4). Multivariate logistic regression analyses showed that area, age, respiratory disease in family, cough in childhood, BMI and cooking using biomass fuel were significantly associated with COPD (table 4).

When the indoor and outdoor concentrations of different gaseous pollutants using various cooking fuels were compared, the concentrations of all measured pollutants $\left(\mathrm{CO}, \mathrm{PM}_{10}, \mathrm{SO}_{2}\right.$ and $\mathrm{NO}_{2}$ ) in the kitchen during biomass fuel combustion were significantly higher than during LPG combustion. The $\mathrm{SO}_{2}$ and $\mathrm{PM}_{10}$ concentrations in biomass fuel combustion were significantly higher than in coal combustion and the CO concentration in coal combustion was significantly higher than in LPG combustion (fig 3). In Yunyan, during biomass fuel combustion, the concentrations of $\mathrm{PM}_{10}, \mathrm{SO}_{2}$ and $\mathrm{NO}_{2}$ in the kitchen were also significantly higher than in the living room but this was not the case for CO. All the concentrations of CO, $\mathrm{PM}_{10}, \mathrm{SO}_{2}$ and $\mathrm{NO}_{2}$ in the kitchen were significantly higher than those measured outdoors (fig 4, left panel). In Liwang there was a similar significant difference in pollutant concentrations in the kitchen, living room and outdoors except for $\mathrm{NO}_{2}$ (fig 4, right panel). It is noticeable that, in comparing rural Yunyan with urban Liwang, the indoor pollutant concentrations were significantly higher in Yunyan but the outdoor concentrations were higher in Liwang with significant differences for $\mathrm{SO}_{2}$ and $\mathrm{PM}_{10}$. The concentration of $\mathrm{SO}_{2}$ in the kitchen of subjects with COPD was significantly higher than in the kitchen of subjects without COPD (fig 5). Using multiple logistic regression analysis, only $\mathrm{SO}_{2}$ was significantly associated with the prevalence of non-smoking women with COPD (OR 1.80, 95\% CI 1.04 to 3.11, p=0.036; table 5).

\section{DISCUSSION}

In order to describe the epidemiology of COPD in southern China and to clarify the role of biomass as a risk factor for COPD, we have completed a large-scale survey of people aged $\geqslant 40$ years in rural and urban Guangdong Province and analysed the relationship between air pollution during biomass combustion and the prevalence of COPD. The indoor and outdoor air pollutants were measured and compared in the epidemiological survey. To the best of our knowledge, this is the first study of the association between biomass fuel indoor air pollution and COPD in China.

The overall prevalence of COPD in the areas studied was $9.4 \%$. The prevalence of COPD in rural Yunyan was significantly higher than in urban Liwang $(12.0 \%$ vs $7.4 \%)$. This may be partly due to other risk factors such as age, sex, smoking, lifetime exposure to environmental tobacco smoke, occupational exposure to dusts, cooking fuels and so on, especially active smoking because the overall prevalence of cigarette smoking in Yunyan was significantly higher than in Liwang (38.4\% vs $35.1 \%$, table 1 ). However, our data showed that there

Table 5 Logistic regression of pollutants for risk of COPD

\begin{tabular}{llrll}
\hline & Crude OR (95\% Cl) & p Value & Adjusted OR (95\% Cl)† & p Value \\
\hline Pollutants* $^{*}$ & $1.27(0.89$ to 1.81$)$ & 0.193 & $1.29(0.83$ to 2.01$)$ & 0.361 \\
$\mathrm{SO}_{2}$ & $4.79(2.51$ to 9.16$)$ & $<0.001$ & $1.80(1.04$ to 3.11$)$ & 0.036 \\
$\mathrm{NO}_{2}$ & $2.27(1.86$ to 2.78$)$ & $<0.001$ & $1.28(0.79$ to 2.09$)$ & 0.321 \\
$\mathrm{PM}_{10}$ & $1.66(1.26$ to 2.19$)$ & $<0.001$ & $1.10(0.93$ to 1.30$)$ & 0.254 \\
$\mathrm{CO}$ & $1.15(1.10$ to 1.20$)$ & $<0.001$ & $1.01(0.98$ to 1.04$)$ & 0.379 \\
\hline
\end{tabular}

$\mathrm{SO}_{2}$, sulphur dioxide; $\mathrm{NO}_{2}$, nitrogen dioxide; $\mathrm{PM}_{10}$, particulate matter with aerodynamic diameter $\leqslant 10 \mu \mathrm{m} ; \mathrm{CO}$, carbon monoxide.

*Scores from principal components analysis of concentrations of $\mathrm{SO}_{2}, \mathrm{NO}_{2}, \mathrm{PM}_{10}$ and $\mathrm{CO}$.

†Adjusted by area, age group, environmental tobacco smoke exposure, occupational exposure to dust, respiratory disease in family, cough in childhood and local exhaust ventilation in kitchen. 
were fewer women smokers in Yunyan than in Liwang $(0.5 \%$ vs $9.5 \%)$, but the prevalence of COPD in non-smoking women in Yunyan was still higher than in Liwang (7.2\% vs $2.5 \%)$. This suggests that other important factors might have contributed to COPD, particularly among non-smoking women in Yunyan.

Univariate and multivariate analyses showed a positive association between COPD and exposure to biomass for cooking. Similar results have also been reported in other smaller surveys or case studies..$^{73}{ }^{14}$ Ekici et al compared the presence of chronic airway diseases in two groups of nonsmoking women aged $\geqslant 40$ years with and without a history of exposure to biomass cooking in Turkey; their findings suggested that biomass smoke pollution was an important contributing factor in the development of chronic airway diseases in non-smoking women living in a rural area.

A significant association was found between COPD and age, but the population in rural Yunyan was younger than that in urban Liwang. Although reported prevalences of passive smoking (77.2\%), lower education level, occupational exposure to dust and no local exhaust ventilation in the kitchen in nonsmoking women in rural Yunyan were higher than those in urban Liwang, multivariable logistic regression analysis showed no significant associations between COPD and these factors in this study (table 4). The lack of a significant association between COPD and occupational exposure to dust in the total population analysis (table 2) is not consistent with previous reports. ${ }^{15}$ It may be because the question about occupational exposure to dust used in our questionnaire was misinterpreted; for example, in rural Yunyan occupational dust mainly comprises grain dust during the harvesting season but the subjects who reported occupational dust exposure were usually exposed to it for only about half a month each year. Such a short duration of exposure might not be enough to cause COPD. Indeed, occupational dust exposure other than grain dust in urban Liwang was much longer in duration than in rural Yunyan. It is thought that long-term exposure to air pollutants may be independent risk factors or effect modifiers for COPD.

Biomass fuels such as crop residues or wood are used in more than half the world's households and a significant proportion of this activity takes place in conditions where much of the airborne effluent is released in the living area. ${ }^{16}$ Exposure to large amounts of biomass fuel smoke may present a health risk that is similar to that from tobacco smoke. ${ }^{17}$ The persons most frequently affected are women who do the cooking for households in rural villages.

Pollutants from biomass combustion are a complicated mixture of aerosol (droplets and solid particles) and gases such as CO, PM, hydrocarbons, $\mathrm{NO}_{2}, \mathrm{SO}_{2}$ and others. ${ }^{16}$ Our study confirmed high concentrations in the kitchen and adjacent living area. The average level of outdoor $\mathrm{SO}_{2}$ and $\mathrm{PM}_{10}$ in Yunyan was significantly lower than in Liwang. The $\mathrm{SO}_{2}$ concentration in the kitchen of subjects with COPD was significantly higher than for those without COPD, and $\mathrm{SO}_{2}$ was significantly associated with the prevalence of non-smoking women with COPD by multiple logistic regression analysis which suggests that biomass fuel combustion might have contributed to COPD. Because there was no major industry leading to outdoor air pollution in Yunyan and the level of road vehicle traffic was low, most of the exposure to air pollution in Yunyan was likely to occur indoors as a result of domestic fuel combustion.

In addition, we found that a higher BMI $\left(\geqslant 24.0 \mathrm{~kg} / \mathrm{m}^{2}\right)$ had a protective effect for COPD. The reason is not clear, but HarikKhan et $a l^{18}$ found a relative risk of developing COPD for the lowest BMI tertile relative to the highest tertile in men of 2.76 (95\% CI 1.15 to 6.59). It is therefore possible that people with a lower BMI are at an increased risk of developing COPD.
In conclusion, the difference in the prevalence of COPD between rural and urban populations in this study, particularly among non-smoking women, suggests that biomass fuel exposure is an important risk factor for COPD. In China the total population exposed to such indoor air pollution is large, and more attention should be paid to improve the cooking stoves and ventilation conditions in rural communities. Interventional studies may be required for stronger evidence of this association and, more importantly, to determine the size of the health benefit achievable from feasible reductions in exposure.

\section{ACKNOWLEDGEMENTS}

The authors thank Associate Professor David M Mannino, University of Kentucky School of Medicine and Dr Ronald Wang, Chinese University of Hong Kong for help in editing the manuscript, Dr Guangqiao Zeng, Guangzhou Institute of Respiratory Disease, for linguistic advice of the final revision and the Ministry of Science and Technology of the People's Republic China; and Department of Science and Technology of Guangdong Province of China for financial support. Special thanks also are given to the interviewers and investigators, Municipal Departments of Liwang District and Yunyan District, the Center of Environmental Monitoring, the Bureau of Environmental Protection of Guangzhou and the Center for Disease Control and Prevention of Guangzhou.

\section{Authors' affiliations}

Shengming Liu, Guangzhou Institute of Respiratory Disease, The First Affiliated Hospital, Guangzhou Medical College, Guangzhou, and Department of Respiratory Medicine, The First Affiliated Hospital of Jinan University, Guangzhou, Guangdong Province, P R China

Yumin Zhou, Jingping Zheng, Nanshan Zhong, Pixin Ran, Guangzhou Institute of Respiratory Disease, The First Affiliated Hospital, Guangzhou Medical College, Guangzhou, Guangdong Province, P R China

Xiaoping Wang, Department of Respiratory Disease of the First Municipal Hospital of Shaoguan, Guangdong Province, P R China

Dali Wang, The Second Hospital of Liwang District of Guangzhou City, Guangdong Province, P R China

Jiachun Lu, Department of Basic Medicine, Guangzhou Medical College, Guangzhou, Guangdong Province, P R China

This study was supported by The Tenth Five-Year Key Project from the Ministry of Science and Technology of the People's Republic of China (2001BA703B03(A)) and the Department of Science and Technology of Guangdong Province of China (B30301).

Competing interests: None.

\section{REFERENCES}

1 Murray CJ, Lopez AD. Alternative projections of mortality and disability by cause 1990-2020: Global Burden of Disease Study. Lancet 1997;349:1498-504.

2 Kim DS, Kim YS, Jung KS, et al. Prevalence of chronic obstructive pulmonary disease in Korea: a population-based spirometry survey. Am J Respir Crit Care Med 2005;172:842-7.

3 Higgins MW. Epidemiology of COPD. Chest 1984;85:3-8S

4 Abbey DE, Burchette RJ, Knutsen SF, et al. Long-term particulate and other air pollutants and lung function in nonsmokers. Am J Respir Crit Care Med 1998;158:289-98.

5 Bruce N, Perez-Padilla R, Albalak R. Indoor air pollution in developing countries: a major environmental and public health challenge. Bull WHO 2000:78:1078-92.

6 Menezes AMB, Perez-Padilla R, Jardim JRB, et al. Chronic obstructive pulmonary disease in five Latin American cities (the PLATINO study): a prevalence study. Lancet 2005;366:1875-81.

7 Ekicia A, Ekicia M, Kurtipek E, et al. Obstructive airway diseases in women exposed to biomass smoke. Environ Res 2005;99:93-8.

8 Perez-Padilla R, Regalado J, Vedal S, et al. Exposure to biomass smoke and chronic airway disease in Mexican women. A case-control study. Am J Respir Crit Care Med 1996;154:701-6.

9 Ng'ang'a LW, Odhiambo JA, Mungai MW, et al. Prevalence of exercise induced bronchospasm in Kenyan school children: an urban-rural comparison. Thorax 1998;53:919-26.

10 Volkmer RE, Ruffin RE, Wigg NR, et al. The prevalence of respiratory symptoms in South Australian preschool children. II. Factors associated with indoor air quality. J Paediatr Child Health 1995;31:116-20.

11 American Thoracic Society. Standardization of spirometry, 1994 update. Am J Respir Crit Care Med 1995;152:1 107-36. 
12 Pauwels RA, Buist AS, Calverley PM, et al. Global strategy for the diagnosis, management, and prevention of chronic obstructive pulmonary disease. NHLBI/ WHO Global Initiative for Chronic Obstructive Lung Disease (GOLD) Workshop summary. Am J Respir Crit Care Med 2001;163:1256-76.

13 Özbay B, Uzun K, Arslan H, et al. Functional and radiological impairment in women highly exposed to indoor biomass fuels. Respirology 2001:6:255-8.

14 Demirtas N, Seyfikli Z, Topçu S. The relationships between traditional biomass combustion and development of COPD in women of Sivas area. Respir Dis 1999;10:156-8.
15 Balmes J, Becklake M, Blanc $P$, et al. Occupational contribution to the burden of airway disease (an official statement of the American Thoracic Society). Am J Respir Crit Care Med 2003;167:787-97.

16 De Koning HW, Smith KR, Last JM. Biomass fuel combustion and health. Bull WHO 1985;63:11-26.

17 Chen BH, Hong CJ, Pandey MR, et al. Indoor air pollution in developing countries. World Health Stat Q 1990;43:127-38.

18 Harik-Khan RI, Fleg JL, Wise RA. Body mass index and the risk of COPD. Chest 2002;121:370-6.

\section{LUNG ALERT}

Pleurodesis with large-particle talc poudrage is safe in malignant pleural effusion

$\Delta$ Janssen JP, Collier G, Astoul P, et al. Safety of pleurodesis with talc poudrage in malignant pleural effusion: a prospective cohort study. Lancet 2007;369:1535-9.

7 alc has been widely used for over 75 years as a sclerosing agent in patients with recurrent malignant pleural effusion. It is probably more effective than other agents, widely available and cheap with minimal side effects. However, recent concerns about patients developing acute respiratory distress syndrome (ARDS) have led to misgivings about its use. Talc, instilled either by slurry or by thoracoscopy, has been shown to produce more than $90 \%$ success in the control of recurrent malignant pleural effusion.

In this open-label, prospective cohort study, which was conducted in 13 European hospitals and one in South Africa, 558 patients with malignant pleural effusion underwent thoracoscopy and talc poudrage with $4 \mathrm{~g}$ talc. Large-particle talc produced in France, with a mean particle size of $24.5 \mu \mathrm{m}$, was used. It was thought not to be ethical to compare small- with large-particle talc as the evidence suggests that talc particle size is the main cause of side effects.

There were no cases of ARDS reported in this study. Eleven (2\%) patients died within 30 days. All deaths were attributed to the diseases rather than the procedure itself. One patient had respiratory failure due to bilateral pneumothoraces; six other patients had non-fatal postthoracoscopy complications. In general, side effects from thoracoscopic pleurodesis were mild. There was a mild increase in temperature and oxygen use, which might be due to mild systemic and lung inflammation caused by talc.

The authors concluded that use of talc for pleurodesis in malignant pleural effusion is safe, and suggest that fears about ARDS are largely unfounded as long as large-particle talc is used.

Marwan Najib

Specialist Registrar in Respiratory Medicine, RAEI Wigan; drmnajib@hotmail.com 